\title{
The Path of Passionate
}

Inquiry: A comment on

Smith, Young, Weathersby

and Andrews

\section{Michael M. Piechowski}

These are stories of four researchers struggling with tasks for which there can be no formal preparation. Young, Weathersby, and Andrews share a background in behavioral research with its reigning paradigm of theoretical pluralism, a paradigm which avoids efforts to resolve incompatibilities and abandon weak or untenable theories. Smith does not share this background. A mathematician turned educational researcher, Smith was raised in a paradigm of pure theory and research and had to discover for himself the paradigm on which Young, Weathersby, and Andrews were bred.

\section{The Outsider's Journey}

Smith's paper provides an illuminating perspective on an outsider's path to the heart of the field. While all four authors are engaged in the life of action ("joining the worlds of contemplation and action"), Smith had to experience an actual rift between the theoretical scientist in him and his new role of a guide to teacher's behavior. His journey from "applying the pure to purifying the applied" brings out sharply issues that recur in debates about the nature of problems in social sciences versus those in the physical sciences. The crux of the matter 
is not that problems are so different, although they very likely are, but that they have been pursued in such distinctly different ways.

Let us retrace Smith's steps in assisting faculty to improve the quality of teaching and learning.

Step 1.

Step 2.

Step 3.

Step 4.

Step 5.

Step 6.

Step 7.

Step 8. Is struck by the significance of learning by doing and by carefully studying one's experience of it. The interplay of action and reflection, of the concrete and of the abstract. 
Step 9. Becomes aware of the reality of individual differences: There are distinct styles of learning and knowing which are stable and specific to individuals.

Step 10. Resumes the search for theory but with a new direction, for any theory anywhere that would accommodate his new perception of what is essential to the work on improving teaching. There are echoes of the despair in Step 5: "I was depressed by the overwhelming number of models, approaches, and perspectives. I was looking for a theoretical framework which would help me make sense of all these various theories."

Step 11. Finds the relevant theory: Attribution theory, a social behavior theory of attitude formation, i.e., of forming judgments on causes, motives, abilities, and so on, from limited information, filtered and altered through the individual's own perspective (experiential history).

Step 12. Quest for research methodology to test the fit of his model - attribution theory as translated to teaching with the facts. The case study approach turns outto be the most appropriate methodology.

\section{The Shared Journey}

If we now compare the steps of Smith's journey with those told by the other three, we find interesting parallels. In regard to the early search for theory (Step 1), perhaps only Weathersby shares it with Smith. For her the relevant theory was adult development theories of transformation. For Andrews, who thrives on bridging incongruities of the pure and the applied, Steps 1-4 are implicit. Because he desires to bring together the experiential and the objective and to bring the clinical and the experimental to bear on the complex task of improving instruction, he assumes implicitly the possibility of a relevant theory and the accessibility of formal research procedures. There are, however, differences of perspective. Andrews, Weathersby, and Young accept "the state of the art"; Smith finds it wanting. Young describes it well: "growing up intellectually and professionally in a milieu of varied and often competing theoretical positions and empirical inter- 
ests," where "all are necessary but none are sufficient." For the insider Young, to be exposed to the extremes of this diversity was "good luck"; for the outsider Smith, it was a state of confusion breeding depression and despair (Steps 5 and 10).

But confusion bordering on despair can occur for a natural scientist as well. Wolfgang Pauli, a physicist and later Nobel prize winner, wrote around 1925: "At the moment physics is again terribly confused. In any case it is too difficult for me, and I wish I had been a movie comedian or something of the sort and had never heard of physics" (Kuhn 1962, p. 84). The continuing confusion of competing theoretical positions in social science is not a function of their youth, as Smith states, but of inability or unwillingness to establish consensus about the central questions in their domain. Given such consensus, the competition would properly be fought under a criterion of the best empirical and theoretical resolution to each of these questions. It is easy to see why only Smith manifested despair.

What saved Andrews, Young, and Weathersby from despair was their ability to transcend enculturation. All four share a focus on the necessity of experiential learning (Steps 9-12). Andrews, in fact, runs the kind of workshops that were the turning point for Smith. Each of them made personal discoveries. Weathersby discovered the effectiveness of relating experience developmentally. Young discovered that thinking and behavior must be considered in an integrated way and also that the context of a process is crucial (very close to attribution theory!). But Smith can be credited with discovering a phenomenon: the natural occurrence that most significant human learning takes place in groups. In his appreciation of the properties of this phenomenon he also saw the teachers' response (willingness or reluctance as an integral part that had to be accounted for.

The sense of phenomenon is as much missing from educational research as is a sense of theory. The phenomenon that struck Smith as essential is seldom addressed by theories and research on learning. The theory he found to be both relevant and rich enough to accommodate the experiential, the interfactional, and the self-evaluative aspects of learning was a social theory, a theory about attitudes. Smith's discovery was aided by his status as an outsider, free of the enculturation which makes one accept the state of affairs rather than question 
its very foundations. Smith's background as a scientist is also important in the way it sharpened his search for discernible properties and a theory applicable to them.

\section{Themes in Common: Teaching and Learning}

These steps uncover certain recurrent themes and regularity of progression in the tanning process of our four heroes:

- the challenge of a complex task: to find ways of improving instruction, ways which work with diverse teachers;

- the acknowledgement that teaching and learning engage individuals in group situations, that the process is interfactional and experiential;

- the conclusion that the teacher is also immersed in the dynamic of the group and so the teachers' own experiential flow is part and parcel of the whole;

- the necessity of immersing oneself in the phenomenon (process) while simultaneously subjecting it to careful scrutiny;

- the acknowledgement that no adequate knowledge of instruction and no adequate improvement is possible without the use of self;

- the necessity of seeking theoretical coherence for experiential knowing (subjective experience as a natural phenomenon accessible to objective formulation).

The convergence of the steps each followed is striking and can be stated very simply. Human learning is socially mediated; social interactions involve the participants' selves - their thoughts, feelings, motives, and manner of attribution; individualities of the participants constitute critical variables; experience has coherence, i.e., stability of form, therefore it can be studied systematically. This fits admirably with Margaret Mead's (1976) distinction of two sources of knowledge in regard to human beings: "It is necessary to recognize that our knowledge of ourselves and of the universe within which we live comes not from a single source but from two sources - from our capacity to explore human responses to events in which we and others participate through introspection and empathy, as well as from our 
capacity to make objective observation on physical and animate nature."

\section{Themes in Tension: Science and Art}

The coherent and inevitable form of their experience clashes with one of Smith's conclusions about teaching, mentioned in Step 5, a conclusion that is often heard: "It is not a science, therefore, it must be art." This usage implies that what we call "science" is well-defined, knowable, carried out by clearly specified procedures; hence, reliable, reproducible, and teachable. Seen as its opposite, "art" would thus mean an undertaking that is ill-defined, unknowable, carried out by unspecified procedures; hence, unreliable, irreproducible and unteachable. Yet artists work extremely hard and with great concentration at what they are trying to produce, be it a dance movement, phrasing a melody, developing a character in a play or in opera, putting together a sculpture, painting a painting, writing a poem. The artist is guided by a very clear sense of what needs to be done, even though it often cannot be made explicit until the work is almost finished (Getzels \& Csikszentmihalyi, 1976). This guiding conception, which Langer (1953) called "the commanding form," closely resembles the scientist's struggle with an unborn idea or image. Thus Darwin was guided in his work by the image of a tree of nature, an image that remained the one constant through several starts and erasures on how the process of evolution of the species come about.

Procedures in art are specified. Every art has its school where people are trained, often more rigorously than in science laboratories. Art is reproducible either as a repeated performance, often of much greater exactitude than a scientific experiment, or as an imitation. Judgements of originality and aesthetic value are highly reliable if the judges are artists or art teachers (Getzels \& Csikszentmihalyi, 1976).

If none of these distinguish art and science, what can that distinction be? It must be the subject matter. Science gives us explanations of the structure of the universe: matter, light, motion, minerals, forms of life, weather (not a very good job there!). Art does not deal with explanations, it presents human motives, passions, triumph or defeat; it expands our perception and awareness in every range in which we 
would follow it: the properties of space, light, sound, movement, human feeling. Art engages the self of the recipient; to contemplate art and savor it one needs to immerse oneself in it.

There is also a difference in language. There are no symbolic conventions by which a work of art can be decoded as mathematics, physics, and chemistry can be. Any formal language is discursive because it can be coded and manipulated according to certain rules. But the "language" of art is non-discursive because a work of art is an organic whole; it presents a complete Gestalt, the analysis of which is possible only after it has been apprehended as a whole (Langer, 1953). Its elements are understood only in relation to the whole work. Langer (1967) proposed that the manner of art is that of prescientific knowledge - the stage when impressions are distilled into an image, very much the way the physicists of Benjamin Franklin's times began to think of electricity as a fluid because their experience with electricity made it seem like something that flows.

\section{Toward Resolution: From Image to Model}

The path of scientific inquiry leads from experiences to impressions and ideas, and then to putting these ideas to test. The process of forming impressions, or images, from experience is the basic process of abstraction (Langer, 1967). It is the path from knowledge of the particular to perception of lawful regularities (Allport, 1942). One of the dimensions in Kolb's model of experiential learning cited by Smith is: from concrete experience and feeling to abstract conceptualization and thinking. Young's image of this process is "tanning of hides" turning a raw product into a functional and elegant material. His leading idea that thinking and behavior must be considered in an integrated way is embodied by the "third floor of Erickson Hall," the place where faculty of diverse, even totally opposing, views were housed together. The images that recur in Weathersby express her efforts "to translate vision into action" - grasping, pulling, and effectual power: "grasping the power of the gestalt," "a necromancer seizing the power of an inward perceptual thread to transform outer reality," "designing instruction to pull developmental changes." Andrew's images are of bridging polarities and wedding incongruities, 
"standing at the borders of several worlds" to have " a continuous supply of incongruent experiences" in order to feed intellectual productivity which is "like an arc of electricity between two poles. These poles must be just the right distance apart to product a Zap!"

An image is an intermediate step leading from the concrete to the abstract. We sometimes think that we can jump from the concrete to the abstract in one leap omitting the work of developing an image, but that is probably not possible. We must remember that the image is not necessarily visual, that every impression is that mental form to which we refer as, "it seems like...," "it feels like...." These are perceptions of qualities and any perceived quality can be expressed as an image, a metaphor, a comparison to a situation of experience that engenders a similar feeling.

When lawful regularities are established one can then proceed to the construction of explanatory models and theories. But the critical step is always formation of an image - the conversion of accumulated knowledge of the particular into its simplified analogue.

The impulse of Andrews, Young, Smith and Weathersby to approach faculty development and teaching improvement through experiential workshops and case study methods reflects their sense of respect for the particular since no knowledge is secure without it. "Not only is an initial acquaintance with particulars necessary for the construction of general principles, but in the last analysis no general principles can ever be applied except to concrete and particular objects. Thus, the individual case stands at the gateway and terminus of generalized knowledge" (Allport, 1942, p. 150). Similarly Young: "The only way to identify all relevant variables and observe their interrelationships is to study a few cases a long period of time, in depth, and from a number of different perspectives. The emphasis should be on validity, not reliability, at least in the stage we find ourselves in the study of college teachers." The recourse to experiential training can be also viewed as a means of generating the particulars that would engender images, prerequisites for construction of models and more advanced conceptions. Thus are science and art joined.

One could say that Smith turned to experiential learning out of his passion for knowledge and discovery, as did Andrews, Weathersby, and Young, but with one difference. Smith did not have to go against 
a methodological paradigm that for several decades denigrated the particular as impressionistic, nonscientific, in short as "art."

The most important lesson is that the improvement of teaching and learning lies in experimentation. Experimentation is not a means to arriving at a more fixed form of instruction but an end in itself, the very method of teaching. It is a discovery method that includes the use of self. Passionate inquiry is the best form of learning and the best form of teaching.

\section{References}

Allport, G.W. The use of personal documents in psychological science. New York: Social Science Research Council, 1942, Bulletin 49.

Getzels, J.W., \& Csikszentmihalyi, M. The creative vision. New York: Wiley, 1976.

Kuhn, T. The structure of scientific revolutions. Chicago: University of Chicago Press, 1962.

Langer, S. Feeling and form. New York: Scribner's, 1953.

Langer, S. Mind: An essay on human feeling (Vol. I). Baltimore: Johns Hopkins University Press, 1967.

Mead, M. Towards a human science. Science, 1976, 191, 903-909. 